\section{Nurudea zhengii Ren, A New Species of the Rhus Gall Aphids (Aphididae: Eriosomatinae: Fordini) from Eastern China}

\author{
Zhu-Mei Ren ${ }^{1, *}$, Xu Su${ }^{2}$, Carol D von Dohlen ${ }^{3}$ and Jun Wen ${ }^{4,1, *}$ \\ ${ }^{1}$ School of Life Science, Shanxi University, Taiyuan 030006, Shanxi, China \\ ${ }^{2}$ Key Laboratory of Medicinal Animal and Plant Resources of the Qinghai-Tibetan \\ Plateau in Qinghai Province, School of Life Science, Qinghai Normal University, \\ Xining 810008, Qinghai, China \\ ${ }^{3}$ Department of Biology, Utah State University, Utah 84322, U.S.A \\ ${ }^{4}$ Department of Botany, National Museum of Natural History, Smithsonian Institution, \\ Washington DC 20013, U.S.A
}

\section{A B S T R A C T}

A new Rhus gall aphid species Nurudea zhengii Ren, sp. nov. collected from the Mountain Qixing in Shangrao County, Jiangxi Province, China is described and illustrated from alate viviparous female. The new species differs from the other Nurudea species in the length and proportion of antennal segments, the structure of antennal secondary sensilla, and the flower-like shape of the galls that are formed on its primary host. Its primary host plant is Rhus hypoleuca, whereas other Nurudea species are on R. chinensis.

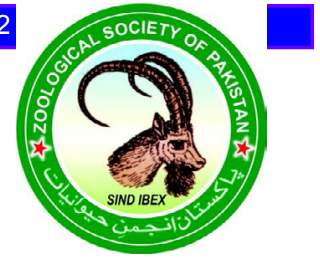

CrossMark
Article Information

Received 19 December 2017

Revised 18 February 2018

Accepted 28 March 2018

Available online 31 August 2018

Authors' Contribution

ZR collected the samples, observed the morphological characters and drafted

the manuscript. XS performed the

experiments, analyzed and interpreted

the data. CDD and JW revised and

polished the manuscript.

Key words

Rhus gall aphid, Nurudea zhengii, New species, Morphology, China.

\section{INTRODUCTION}

$\mathrm{T}$ he Rhus gall aphids refer to a lineage of hostalternating aphids that live on species of Rhus (sumacs) as their primary host, on which they induce galls known as Woo-pei-tsze or Chinese gall (Bell, 1851; Tang and Tsai, 1957). The first species described in this group was recorded from China as Aphis chinensis (Bell, 1851); subsequently, a similar species was described from North America. Although initially considered the same species, they were later recognized as members of different genera by various taxonomists (Fitch, 1866; Lichtenstein, 1883; Baker, 1917; Arshad et al., 2017). Eastop and Lambers (1976) designated the species from China and North America as Schlechtendalia chinensis (Lichtenstein, 1883) and Melaphis rhois (Fitch, 1866), respectively. Additional genera and species of this group from eastern Asia were described and analyzed (Matsumura, 1917; Tsai and Tang, 1964; Xiang, 1980; Tang, 1986). So far, six genera and 12 species (the genus Kaburagia including three subspecies) have been recognized in this group

\footnotetext{
* Corresponding authors: zmren@sxu.edu.cn; wenj@si.edu

0030-9923/2018/0006-2087 \$ 9.00/0

Copyright 2018 Zoological Society of Pakistan
}

(Eastop and Lambers, 1976; Zhang et al., 1999; Yang et al., 2010; Ren et al., 2013, 2017), and they have been placed in the subtribe Melaphidina of tribe Fordini (Hemiptera, Aphididae, Eriosomatinae) (Eastop and Lambers, 1976; Blackman and Eastop, 1994; Favret, 2013). Matsumura (1917) erected the genus Nurudea based on Nurudea ibofushi from Japan, and distinguished this species from Schlechtendalia chinensis by the regularly ringed secondary sensoria on the $3^{\text {rd }}$ antennal joint. Tsai and Tang (1964) described N. sinica as closely allied to $N$. ibofushi, noting that they differ in the structure of sensoria on the apical two joints of the antennae. Eastop and Lambers (1976) synonymized the two species as N. ibofushi. Meanwhile, Matsumura (1917) described two species $N$. shiraii and $N$. yanoniella under the new genus Nurudeopsis, which was subsequently merged into Nurudea by later taxonomists (Eastop and Lambers, 1976; Zhang et al., 1999). Therefore, the genus Nurudea currently includes three species: $N$. ibofushi, $N$. shiraii and $N$. yanoniella from China and Japan, and all of them form galls on their primary host plant Rhus chinensis.

In 2009, we collected several galls formed by an aphid species feeding on Rhus hypoleuca Champion ex Bentham in China. After the morphological examinations, we concluded that the collections are similar to the two species, N. shiraii and N. yanoniella, and should be 
recognized as a new species of Nurudea. Here, we formally described this new species.

\section{MATERIALS AND METHODS}

\section{Materials}

Samples of galls were collected from leaf rachises of Rhus hypoleuca on the Mountain Qixing in Shangrao County, Jiangxi Province, China in 2009. Slide-mounted specimens of 15 alate viviparous females from the same gall were used for morphological observations. The remaining samples were observed as references. The holotype and paratypes of the new species (alate viviparous female) and host-plant vouchers (Ren and $\mathrm{Li} \mathrm{A} 402$ and Ren and $\mathrm{Li}$ P402, respectively) were deposited at School of Life Science, Shanxi University, Taiyuan, China.

\section{Methods}

Freshly collected aphid samples were immersed in $70 \%$ ethanol, then macerated $2-3$ min in $15 \% \mathrm{KOH}$ solution before making permanent slides. Adult alate viviparous specimens were cleared and mounted individually in Canada balsam on microscope slides according to the techniques described by Maw and Foottit (1998). Morphological analyses were performed using a stereomicroscope and an electron microscope, and measurements were taken using a Leica DM2500B microscope.

Aphid morphology was characterized by measuring several morphological features and ratios, and descriptive qualitative features. A total of 50 morphological characters including 20 quantitative characteristics, nine ratios from two measured characters, and the qualitative features from head, thorax and abdomen of the 15 alate adults were evaluated. Aphid terminology in this paper follows Quednau (2003) and Qiao et al. (2005). The unit of measurements is millimeters $(\mathrm{mm})$.

\section{Nurudea zhengii Ren sp. nov.}

(Figs. 1 and 2)

\section{Diagnosis}

The body of alate viviparous females oval, surface smooth. Head, thorax and abdomen without wax plates, middle frons curved. Antennae 5-segmented, smooth, processus terminalis one-fourth as long as base of the segment V. Rostrum short and small. First tarsal chaetotaxy: 3, 3, 3. Siphunculi absent. Fore wings with four oblique veins, media veins unbranched. Cauda halfmoon shaped, smooth. Anal plate oblong.
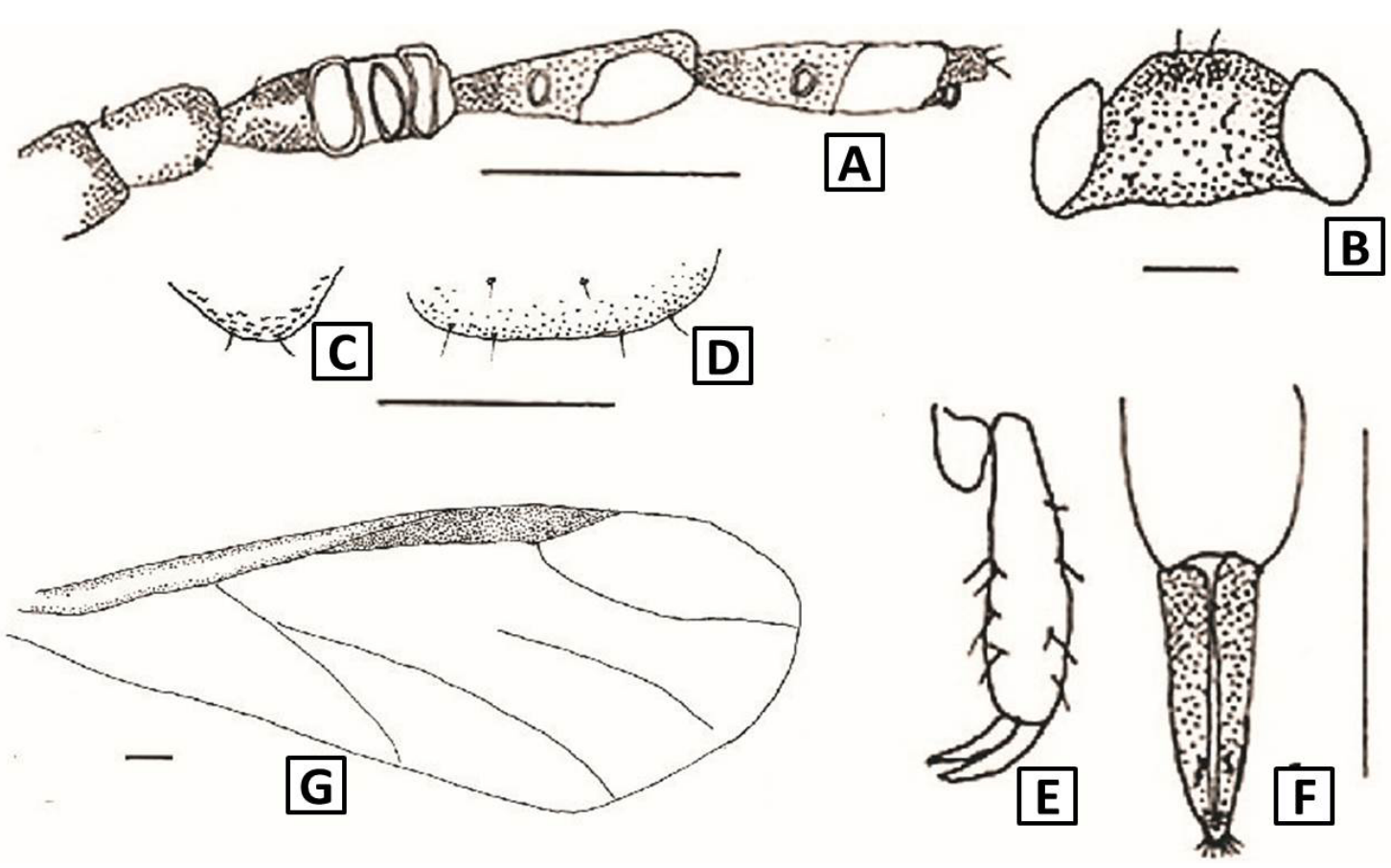

Fig. 1. Morphology of Nurudea zhengii Ren sp. nov. alate viviparous female: A, antennal segments; B, dorsal view of head; C, hind tarsal segments; D, ultimate rostral segments; E, cauda; F, anal plate; G, forewing. Scale bars $=0.10 \mathrm{~mm}$. 


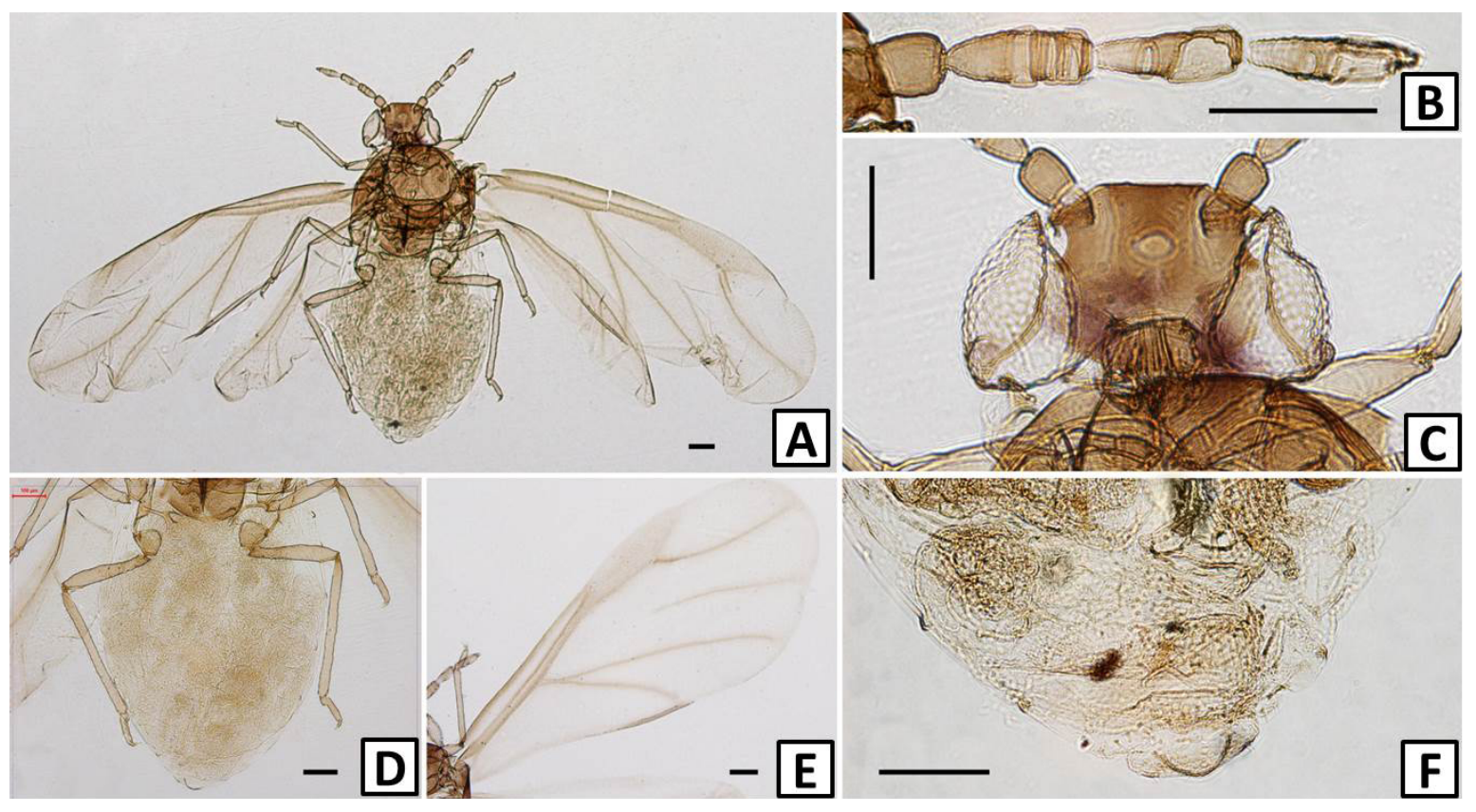

Fig. 2. Morphological characters of Nurudea zhengii Ren sp. nov. alate viviparous female: A, dorsal view of body; B, antennal segments; $\mathbf{C}$, dorsal view of head; $\mathbf{D}$, dorsal view of abdomen; $\mathbf{E}$, fore wing; $\mathbf{F}$, siphunculus. Scale bars $=0.10 \mathrm{~mm}$.

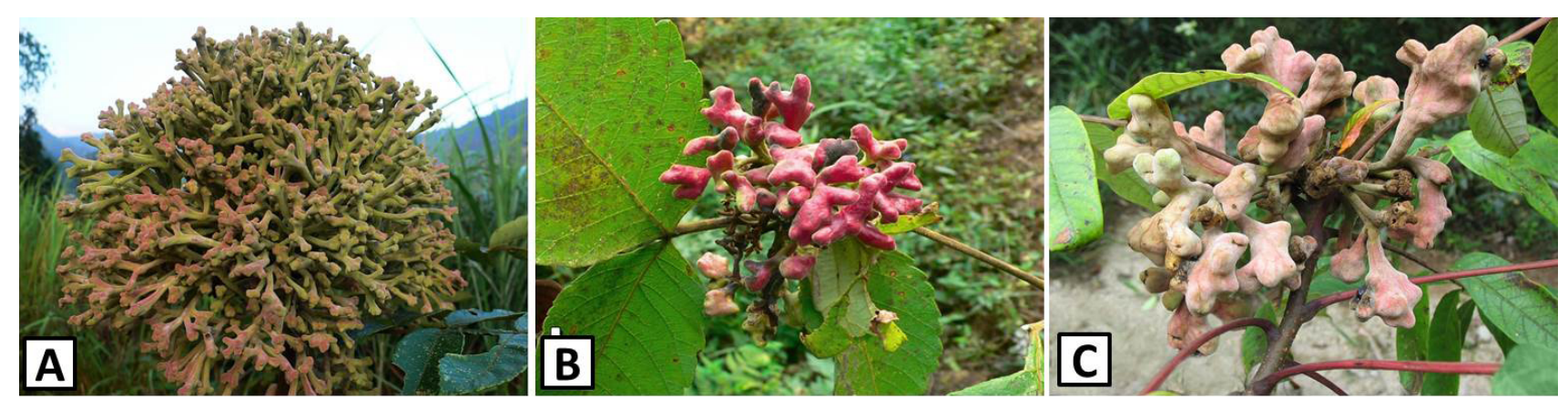

Fig. 3. Galls formed by three Nurudea aphid species. A, N. shiraii; B, N. yanoniella; $\mathbf{C}, N$. zhengii. The diameter of the gall formed by $N$. shiraii in real life is approximately 2-3 times larger than that of $N$. yanoniella and N. zhengii.

\section{Description}

Alate viviparous females oval (Fig. 2). Head and thorax dark brown, abdomen tinge without stripes. Antennae, rostrum and each segment of legs brown, cauda and anal plate light brown. Body surface smooth, front margins of dorsum of head with one pair of small round wax plates and each with 4-6 waxy cells. Thorax and abdomen without wax plates, spiracle round to oval, open or closed. One pair of hairs on the head top and 4-6 pairs of dorsal setae on head. One pair of hairs on the spinal of abdominal tergite I, 4-8 hairs on abdominal tergite III, and length of abdominal tergite I and abdominal tergite III about $0.25-0.50$ and $1.33-4.00$ times as long as the widest diameter of antennal segment III, respectively. Middle frons curved, antennae 5-segmented, smooth, entire length $0.32-0.35$ and $0.45-0.55$ times as long as body; antennal segment III $0.07-0.09$, 5-9 times as long as the diameter of the base of the segment, length in proportion to segments I-V: 28-41: 44-60: 100: 88-106: 75-120+1950 , respectively. Processus terminalis one-fourth as long as base of the segment V, antennal segment III with three circular secondary sensoria, and antennal segments IV and $\mathrm{V}$ with one small and one large oval secondary sensoria, respectively. Antennal setae short and pointed, segments II and III each with 2 or 3 setae, respectively, and apex of processus terminalis with three short pointed setae. Rostrum short and small, not reaching the base of the middle coxae, rostral segment IV $+\mathrm{V}$ sphenoid, 0.06-0.08 
in length, and 1.00-1.60 times as long as the second hind tarsal segment, with two pairs of primary and one pair of accessory setae. Hind femur 0.23-0.28, and 2.63-3.06 times as long as antennal segment III, hind tibia 0.35-0.47, and 0.49-0.69 times as long as body. Length of setae on hind tibia $0.01,0.25-0.40$ times as long as middle width of the tibia. First tarsal chaetotaxy: 3, 3, 3. Siphunculi absent. Fore wings with four oblique veins, media veins unbranched, and two cubitus veins converging at the base. Cauda half-moon shaped, smooth, and 0.50-0.75 times as long as its basal width, with 2 or 3 short setae. Anal plate oblong, with 5-9 short setae, and genital plate transversely oval with 14-20 short setae.

\section{Biology}

The galls of this aphid species are formed on the leaves of the apical part of the stem of Rhus hypoleuca. They are rosy red and flower-like with branches irregularly from the base. The shapes of galls were similar to those formed by Nurudea shiraii, measuring approximately 120 by $100 \mathrm{~mm}$. The alate viviparae appear in late September. The mature galls formed by three Nurudea species on their Rhus primary hosts are shown in Figure 3.

\section{Comments}

Nurudea zhengii Ren, sp. nov. is closely related to the two other species of Nurudea, N. shiraii and N. yanoniella, and it is readily distinguished from the two congeneric species by the length of antennal segments, the secondary sensoria on the antennal segments, the shape of the gall formed on Rhus host plants, and the species of the primary host plant. Compared to $N$. shiraii and $N$. yanoniella, $N$. zhengii differs in the following points: antennal segment III and IV have nearly the same length as the base of antennal segment $\mathrm{V}$, antennal segment III with three circular secondary sensoria, and antennal segments $\mathrm{IV}$ and $\mathrm{V}$ with one small and one large oval sensorium, respectively, and its primary host plant is $R$. hypoleuca. Therefore, the morphological data support the recognition of $N$. zhengii as a new species in Nurudea.

\section{Key to Nurudea species (alate viviparous female)}

1. Segment III subequal to segment V, segment IV shortest, segment V with a large oval secondary sensorium, galls single-celled............. ibofushi - Antennal segments III-V each gradually increasing its length, with a few round incomplete secondary sensoria, galls multi-chambered

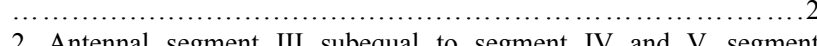
III with three ringed secondary sensoria, segments IV and $\mathrm{V}$ each with one oval secondary sensoria, galls rosy red, colonizing Rhus hypoleuca..................................................... zhengii
- Antennal segments III-V prominently different in length, IV and $\mathrm{V}$ each with a few broader incomplete ringed secondary sensoria, colonizing Rhus chinensis...............3 3. Antennal segment $\mathrm{V}$ longest, nearly twice as long as segment III, segments III-V each with three or four broad incomplete rings, galls not prominently reddish.............................................................. shiraii - Antennal segment III somewhat shorter than segment V, but distinctly longer than segment IV, segments III-V each with more than five distinct annulations, galls rosy red. .N. yanoniella

Table I.- Biometric measurements of alate viviparae Nurudea zhengii collected in Jiangxi, China. Values are means with standard deviation.

\begin{tabular}{|c|c|}
\hline \multirow[t]{2}{*}{ Parts* } & Alate viviparae $(n=15)$ \\
\hline & Mean \pm SD (Range) \\
\hline \multicolumn{2}{|l|}{$\begin{array}{l}\text { Length (mm) } \\
\text { (m) }\end{array}$} \\
\hline Body length & $1.38 \pm 0.065(1.26-1.48)$ \\
\hline Body width & $0.64 \pm 0.022(0.60-0.67)$ \\
\hline Whole antennae & $0.34 \pm 0.014(0.32-0.35)$ \\
\hline Ant. I & $0.03 \pm 0.004(0.02-0.03)$ \\
\hline Ant. II & $0.04 \pm 0.003(0.03-0.05)$ \\
\hline Ant. III & $0.08 \pm 0.006(0.07-0.09)$ \\
\hline Ant. IV & $0.08 \pm 0.005(0.07-0.09)$ \\
\hline Ant. $\mathrm{Vb}$ & $0.08 \pm 0.010(0.07-0.09)$ \\
\hline PT & $0.02 \pm 0.007(0.01-0.04)$ \\
\hline URS & $0.07 \pm 0.006(0.06-0.08)$ \\
\hline Hind femur & $0.26 \pm 0.015(0.23-0.28)$ \\
\hline Hind tibia & $0.38 \pm 0.036(0.35-0.47)$ \\
\hline $2 \mathrm{HT}$ & $0.06 \pm 0.005(0.05-0.07)$ \\
\hline Cauda & $0.03 \pm 0.003(0.02-0.04)$ \\
\hline BW Cauda & $0.04 \pm 0.008(0.03-0.06)$ \\
\hline Ant. III BW & $0.01 \pm 0.003(0.01-0.02)$ \\
\hline MW Hind tibia & $0.03 \pm 0.002(0.02-0.03)$ \\
\hline Cephalic setae & $0.004 \pm 0.001(0.002-0.06)$ \\
\hline Setae on Ant. III & $0.005 \pm 0.002(0.003-0.06)$ \\
\hline Setae on Hind tibia & $0.01 \pm 0(0.01)$ \\
\hline \multicolumn{2}{|l|}{ Ratio } \\
\hline Whole antennae/body & $0.25 \pm 0.014(0.22-0.28)$ \\
\hline Hind femur/Ant. III & $3.10 \pm 0.245(2.63-3.50)$ \\
\hline Hind tibia/body & $0.28 \pm 0.029(0.25-0.35)$ \\
\hline PT/Ant. Vb & $0.24 \pm 0.154(0.15-0.25)$ \\
\hline $\mathrm{URS} / 2 \mathrm{HT}$ & $1.25 \pm 0.181(1.00-1.60)$ \\
\hline Cauda/BW Cauda & $0.60 \pm 0.102(0.50-0.75)$ \\
\hline Cephalic setae/Ant. III BW & $0.40 \pm 0(0.40)$ \\
\hline Setae on Ant. III/Ant. III BW & $0.05 \pm 0(0.05)$ \\
\hline $\begin{array}{l}\text { Setae on hind tibia/MW } \\
\text { Hind tibia }\end{array}$ & $0.33 \pm 0.045(0.25-0.40)$ \\
\hline
\end{tabular}

Ant. I-IV, antennal segments I-IV; Ant. Vb, base of antennal segment V; PT, processus terminalis; Ant. III; BW, basal width of antennal segment III; URS, ultimate rostral segment; 2HT, second hind tarsal segment; MW hind tibia, mid-width of hind tibia; BW Cauda, basal width of cauda. 


\section{Etymology}

The new species was named in honor of Professor Zhe-Min Zheng for his outstanding contribution to the systematic entomology.

\section{Type material}

Holotype, alate viviparous female, with labels as follows: China, Jiangxi Province, Shangrao County, Qixing mountain, 1240 m, N 2757'52.6", E11750'40.3”, 26 Sept. 2009, on Rhus hypoleuca, Coll. Number Ren and $\mathrm{Li}$, A402, deposited at School of Life Science, Shanxi University, Taiyuan, China.

Paratypes, 30 alate viviparous females with the same collection data as the holotype, deposited at School of Life Science, Shanxi University, Taiyuan, China.

\section{Distribution}

China, Jiangxi Province, Shangrao County, Qixing mountain.

\section{Host}

Primary host

Rhus hypoleuca (Anacardiaceae).

\section{Secondary host}

Unknown, but, as for other Rhus gall aphids, it is almost certainly a moss.

\section{ACKNOWLEDGEMENTS}

We thank Gexia Qiao for providing the guidance for the observation of the morphological characters and Liyun Jiang for making slides and observation of the aphid samples. This work was supported by the National High Technology Research and Development "863" Program under Grant 2014AA021802; the National Natural Science Foundation of China under Grant 31170359; the HundredTalent Project in Shanxi Province; the Endowment Program of the Smithsonian Institution; the Global Genome Initiatives (GGI); the Laboratories of Analytical Biology and the Small Grants Program of the National Museum of Natural History, the Smithsonian Institution.

\section{Statement of conflict of interest}

Authors have declared no conflict of interest.

\section{REFERENCES}

Arshad, M., Khan, H.A.A., Hafeez, F., Sherazi, R. and Iqbal, N., 2017. Predatory potential of Coccinella septempunctata L. against four ahid species. Pakistan J. Zool., 49: 755-759.
Baker, A.C., 1917. On the Chinese gall (Aphididae Hom.). Entomol. News, 28: 385-393.

Bell, J., 1851. Chinese galls. J. Pharmaceut., 10: 128.

Blackman, R.L. and Eastop, V.F., 1994. Aphids on the world's tree: An identification and information guide. CAB International Association with the Natural History Museum, Wallingford, UK, pp. 986.

Eastop, V.F. and Lambers, D.H.R., 1976. Survey of the world's aphids. The Hague, Netherlands, pp. 573.

Favret, C., 2013. Aphid species file, Version 1.0/4.1. http://Aphid.SpeciesFile.org.

Fitch, A., 1866. Sumac gall-aphis: Byrsocrypta rhois (order Homoptera, family Aphidae). N. Y. State Agric. Soc., 17: 73.

Lichtenstein, J., 1883. Schlechtendalia chinensis. Entomol. Soc. Stettin, 64: 242.

Matsumura, S., 1917. A collection of essays for Mr. Yasushi Nawa, written in commemoration of his sixtieth Birthday (eds. K. Nagano). Gifu, Japan, pp. 75-85.

Maw, E. and Foottit, R., 1998. The aphids of British Columbia: Methods for the collecting, preparation and study of aphid specimens. http://www.zoology. ubc.ca/ mawe/bcaphid (accessed 20 March 2007).

Qiao, G.X., Zhang, G.X. and Zhong, T.S., 2005. Fauna sinica insecta, Vol. 41: Drepanosiphidae. Science Press, Beijing, pp. 476.

Quednau, F.W., 2003. Atlas of the Drepanosiphine aphids of the World. Part II: Panaphidini Oestlund, 1923-Panaphidina Oestlund, 1923 (Hemiptera: Aphididae: Calaphidinae). Am. entomol. Inst., 72: 1-301.

Ren, Z.M., Zhong, Y., Kurosu, U., Aoki, S., Ma, E.B., von Dohlen, C.D. and Wen, J., 2013. Historical biogeography of eastern Asian-eastern North American disjunct Melaphidina aphids (Hemiptera: Aphididae: Eriosomatinae) on Rhus hosts (Anacardiaceae). Mol. Phylogenet. Evol., 69: 11461158. https://doi.org/10.1016/j.ympev.2013.08.003

Ren, Z.M., Harris, A.J., Dikow, R.B., Ma, E.B., Zhong, Y. and Wen, J., 2017. Another look at the phylogenetic relationships and intercontinental biogeography of eastern Asian - North American Rhus gall aphids (Hemiptera: Aphididae: Eriosomatinae): Evidence from mitogenome sequences via genome skimming. Mol. Phylogenet. Evol., 117: 102-110. https://doi.org/10.1016/j.ympev.2017.05.017

Tang, C. and Tsai, P.H., 1957. Studies on the Chinese gallnuts of Meitan, Kweichow. Acta Entomol., 7: 131-142.

Tang, C., 1986. The genus Meitanaphis and a new 
species from Chinese gallnut aphids. Research Report on Chinese Gallnuts, pp. 1-39.

Tsai, P.H. and Tang, C., 1964. The classification of the Chinese gall aphids with descriptions of three new genera and six new species from Meitan, Kweichow. Ecol. Ent., 97: 405-418.

Xiang, H., 1980. Studies of Chinese gall-nut aphids on Rhus potaninii Maxim. Entomotaxonomia, 2: 303313.

Yang, Z.X., Chen, X.M., Havill, N.P., Feng, Y. and
Chen, H., 2010. Phylogeny of Rhus gall aphids (Hemiptera: Pemphigidae) based on combined molecular analysis of nuclear $E F-1 \alpha$ and mitochondrial COII genes. Ent. Sci., 13: 351-357. https://doi.org/10.1111/j.1479-8298.2010.00391.x Zhang, G.X., Qiao, G.X., Zhong, T.S. and Zhang, W.Y., 1999. Fauna sinica insecta, Vol. 14, Homoptera: Mindaridae and Pemphigidae. Science Press, Beijing. 